\title{
Atomic force microscopy studies of the adhesive properties of DPPC vesicles containing $\beta$-carotene*
}

\author{
Dominika Augustyńska1, Małgorzata Jemioła-Rzemińska², Kvetoslava Burda and \\ Kazimierz Strzałka2® \\ ${ }^{1}$ AGH University of Science and Technology, Faculty of Physics and Applied Computer Science, Kraków, Poland; ${ }^{2}$ Jagiellonian University, Faculty \\ of Biochemistry, Biophysics and Biotechnology, Kraków, Poland
}

\begin{abstract}
A role of carotenoids as modulators of physical properties of model and biological membranes has been already postulated. However, there is a lack of information on the influence of these pigments on interactions between the lipids which form such membranes. This paper applies atomic force microscopy (AFM) in to study the effects of $\beta$-carotene on the adhesion properties of DPPC multilamellar liposomes. This allowed us to gain, for the first time, a direct insight into the interactions between the components in model systems on a molecular level. We observe that the adhesive forces in DPPC multilamellar liposomes containing $1 \mathrm{~mol} \%$ of $\beta$-carotene decrease exponentially with increasing temperature, and that at about $37^{\circ} \mathrm{C}$ they diminish. In the case of pure liposomes the decline in adhesion is of a different nature and the adhesive forces disappear at $34^{\circ} \mathrm{C}$. The adhesive forces are about 5 times higher at $31^{\circ} \mathrm{C}$ in the presence of $\beta$-carotene than in its absence. However, measurements using differential scanning calorimetry (DSC) showed a shift of the lamellar-to-undulled-lamellar phase transition toward lower temperatures by about $0.8 \pm 0.2^{\circ} \mathrm{C}$ in a system containing $\beta$-carotene. The enthalpy changes $(\Delta \mathrm{H})$ of this transition are similar for both systems. For the main transition, gel-to-liquid crystalline, the peak is shifted by about $0.5 \pm 0.1^{\circ} \mathrm{C}$, and $\Delta \mathrm{H}$ decreases by about $30 \%$ in liposomes treated with $\beta$-carotene in comparison to pure liposomes. Our results suggest increased cooperation between liposome components in a system with enriched $\beta$-carotene, which cause a change in phase transition temperatures. Moreover, these interactions are very sensitive to temperature.
\end{abstract}

Key words: liposome adhesion, thermal transition, dipalmitoylphosphatidylcholine, $\beta$-carotene, atomic force microscopy

Received: 19 November, 2011; accepted: 01 March, 2012; available on-line: 17 March, 2012

\section{INTRODUCTION}

Carotenoids, as well as acting as antenna pigments, are known to protect the photosynthetic apparatus against photooxidative stress by being active in the processes of energy dissipation, the scavenging of free radicals and oxidizing agents (Britton et al., 2008; Telfer et al., 2008). It has been also suggested that carotenoids may modulate the physical properties of photosynthetic membranes (see Gruszecki \& Strzałka, 2005 for a review). It has been postulated that the influence of carotenoids on the stability of biological membranes can be also very important in activity promoting health in addition to other functions already recognized (Burton \& Ingold, 1984; Bendich, 1993). $\beta$-carotene is one of the most abundant carotenoids occurring in fruits and vegetables. Its interactions with lipid membranes have been intensively studied and the results provide information about the orientation of this pigment in lipid bilayers (Jemioła-Rzemińska et al., 2005). Moreover, different types and degrees of structural perturbations of lipid systems due to the presence of $\beta$-carotene have been demonstrated (Suwalsky et al., 2002). In recent years the influence of carotenoids on the fluidity of model membranes have been extensively studied. For instance it has been shown that the penetration depth of $\beta$-carotene in the lipid bilayer depends on the degree of lipid unsaturation (Atanaska \& Popova, 2010; Iglič 2011). However, direct measurements of adhesionrelated $\beta$-carotene interactions with the lipids that form biological membranes are missing.

In this work we focus on the adhesive interactions between $\beta$-carotene and 1,2-dihexadecanoyl-sn-glycero-3-phosphocholine (DPPC) in the form of liposomes. These forces are regarded as the most crucial for membrane integrity (Duzgunes \& Nir, 1999; Bakowsky et al., 2008). The results obtained in this study may be useful in engineering drug delivery cargo, especially in looking for new ways to improve of lipoplexe stability. Atomic force microscopy (AFM) gives a unique opportunity to study the topography and mechanical properties of natural and artificial membranes and liposomes, including elasticity and adhesion (Sanchez \& Badia, 2003; De Souza \& Teschke, 2003; Yang \& Tsay, 2007, Roiter et al., 2009). Differential scanning calorimetry (DSC) is used to monitor differences in the phase transitions in DPPC liposomes with and without $\beta$-carotene. The temperatures of phase transitions in liposomes are sensitive to preparation procedures, therefore DSC is applied to examine the quality of liposomes (Biltonen \& Lichtenberg, 1993).

\section{MATERIALS AND METHODS}

Preparation of phospholipid vesicles. $\beta$-carotene and 1,2-dipalmitoyl-sn-glycero-3 phosphocholine

e-mail: kazimierzstrzalka@gmail.com

*Presented at the 16th International Symposium on Carotenoids, 17-22 July, 2011, Kraków, Poland

Abbreviations: AFM, atomic force microscopy; DPPC, 1,2-dihexadecanoyl-sn-glycero-3-phosphocholine; DSC, differential scanning calorimetry; $T_{m^{\prime}}$ temperature of gel-to-liquid crystalline phase transition (main transition); $T_{p}$ temperature of lamellar-to-undulledlamellar phase transition (pretransition). 
(DPPC) from Sigma were used without further purification. Appropriate amounts of lipid and $\beta$-carotene dissolved in chloroform were mixed in a glass test tube. The organic solvent was gently evaporated to dryness under a stream of gaseous nitrogen until a thin film on the wall of the test tube was formed. Then deionized water was added and multilamellar vesicles (MLV) were formed by vortexing for 10 minutes at a temperature of $50^{\circ} \mathrm{C}$ i.e., above the main phase transition temperature $\left(T_{\mathrm{m}}\right)$ of pure DPPC. The final DPPC concentration was $1 \mathrm{mM}$ and the $\beta$-carotene content in the samples was $1 \mathrm{~mol} \%$.

Preparation of sample for AFM measurements. A glass slide to be used as a substrate was kept for $1 \mathrm{~h}$ in a chromic acid cleaning mixture $\left(\mathrm{K}_{2} \mathrm{Cr}_{2} \mathrm{O}_{7}\right.$ in $\left.\mathrm{H}_{2} \mathrm{SO}_{4}\right)$. Then it was flushed with distilled water and dried by evaporation in air at $20^{\circ} \mathrm{C}$. A drop of DPPC mixture containing $1 \mathrm{~mol} \%$ of $\beta$-carotene was put on the glass surface and evaporated with a nitrogen stream. For the DPPC liposomes the preparation procedure was the same.

Differential scanning calorimetry (DSC). Differential scanning calorimetry measurements were performed using a Nano DSC device (TA Instruments). The sample cell was filled with $400 \mu \mathrm{l}$ of MLV suspension and, as a reference, an equal volume of deionized water was used. The cells were sealed and equilibrated for about 10 min at below starting temperature. Heating/cooling rates were $1^{\circ} \mathrm{C}$ per minute and the scans were recorded within a range of $25-50^{\circ} \mathrm{C}$. Heating scans were carried out first. The reference scan was subtracted from the sample scan. Each data set was analyzed and the values of transitions temperature were calculated using a software package supplied by TA Instruments. The accuracy of the temperature was $\pm 0.1^{\circ} \mathrm{C}$.

Atomic force microscopy (AFM). Imaging and force curve measurements were performed with atomic force microscopy AFM 5500 (Agilent, USA). Silicon nitride probes with a triangular soft cantilever (Veeco, model MLCT-AUHW) with a nominal value of the spring constant of $0.01 \mathrm{~N} / \mathrm{m}$ and $0.1 \mathrm{~N} / \mathrm{m}$ being used in the contact and non-contact topography measurements, respectively. A Lakeshore 332 temperature controller and a standard hot sample plate (Agilent) were used to heat and control the sample temperature to an accuracy of $0.1^{\circ} \mathrm{C}$. The heating rate was $1^{\circ} \mathrm{C}$ per minute. Temperature dependent measurements of the adhesive forces were performed within a temperature range from 29 to $38^{\circ} \mathrm{C}$. The sample was always incubated at a given temperature for $10 \mathrm{~min}$ before the measurement. Liposome mixtures were prepared a day before measurement and they were stored at $4^{\circ} \mathrm{C}$.

\section{RESULTS AND DISCUSSION}

\section{Differential scanning calorimetry measurements}

The DSC heating profiles of pure DPPC multilamellar vesicles and those containing $\beta$-carotene are presented in

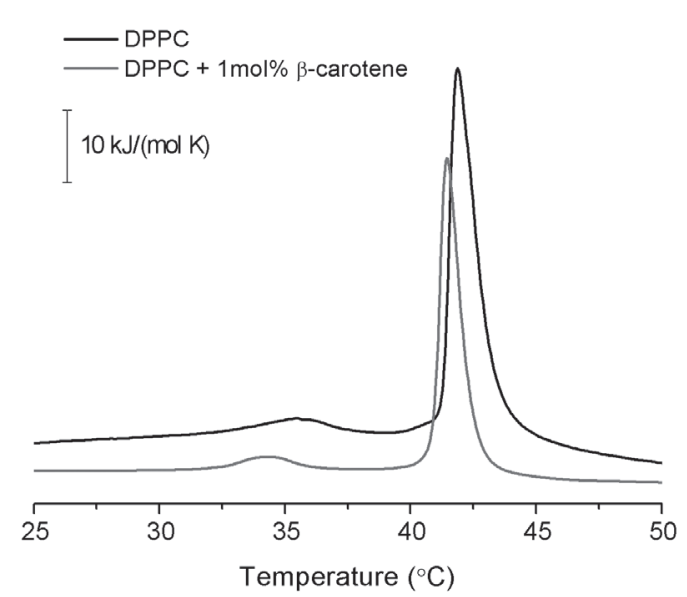

Figure 1. Representative DSC heating thermograms obtained for multilamellar DPPC liposomes and DPPC liposomes containing $1 \mathrm{~mol} \%$ of $\beta$-carotene.

Fig. 1. The thermodynamic parameters evaluated from the experimental data and the characteristic transition temperatures detected for these systems are shown in Table 1.

In the temperature range of $25-50^{\circ} \mathrm{C}$, fully hydrated DPPC liposomes, in the absence of any additives, undergo a sharp main-transition at about $41 . \pm 0.1^{\circ} \mathrm{C}$, with an average enthalpy change $(\Delta \mathrm{H})$ of about $33.9 \mathrm{~kJ}$ $\mathrm{mol}^{-1}$. This transition corresponds to the conversion of the rippled gel phase $\left(\mathrm{P}_{\beta}{ }^{\prime}\right)$ to the lamellar liquid-crystal $\left(\mathrm{L}_{\alpha}\right)$ phase. The smaller transition, called pretransition (lamellar-to-undulled-lamellar phase transition), occurs at $35.2^{\circ} \mathrm{C}$ and is characterized by $\Delta \mathrm{H}=3.69 \mathrm{~kJ} \mathrm{~mol}^{-1}$. Here, the transition temperatures correspond to the transition peak at the maximal peak heat and the transition enthalpies correspond to the integrated area under the peak divided by the lipid concentration.

From the DSC profiles depicted in Fig. 1, it is clearly seen that the incorporation of $\beta$-carotene alters the thermotropic behaviour of the DPPC bilayers. $1 \mathrm{~mol} \%, \beta$-carotene causes a shift of $T_{\mathrm{m}}$ towards lower temperatures by about $0.4^{\circ} \mathrm{C}$ and a decrease in enthalpy by about $20 \%$ as compared with pure liposomes in the case of the main transition. In the case of pretransition it results in a temperature downshift of about $1.0^{\circ} \mathrm{C}$ and an enthalpy decrease of about $30 \%$. These changes suggest that this concentration of $\beta$-carotene has a more pronounced effect on pretransition than on the main transition, which indicates a stronger distortion of DPPC packing in the gel state. These data are in agreement with our previous report (KosteckaGugała et al., 2003).

The transition pathways in heating and cooling (not shown) scans display significant hysteresis, arising from a different lateral mobility of acyl chains in the gel and in the liquid crystal phase. Moreover, the hysteresis is different for these two systems.

Table 1. The temperatures of the phase transitions $\left(T_{\mathrm{p}}, T_{\mathrm{m}}\right)$ and values of enthalpy $(\Delta \mathrm{H})$ and entropy changes $(\Delta \mathrm{S})$ evaluated from the calorimetric measurements obtained for multilamellar DPPC liposomes and DPPC liposomes containing 1 mol\% of $\beta$-carotene.

\begin{tabular}{llllllll}
\hline Sample & Scan cycle & $T_{\mathrm{p}}\left({ }^{\circ} \mathrm{C}\right)$ & $\Delta \mathrm{H}(\mathrm{kJ} / \mathrm{mol})$ & $\Delta \mathrm{S}(\mathrm{kJ} /(\mathrm{mol} \cdot \mathrm{K}))$ & $T_{\mathrm{m}}\left({ }^{\circ} \mathrm{C}\right)$ & $\Delta \mathrm{H}(\mathrm{kJ} / \mathrm{mol})$ & $\Delta \mathrm{S}(\mathrm{kJ} /(\mathrm{mol} \cdot \mathrm{K}))$ \\
\hline DPPC & Heating & $35.2 \pm 0.1$ & $3.7 \pm 0.8$ & $0.012 \pm 0.002$ & $41.8 \pm 0.1$ & $33.9 \pm 0.8$ & $0.108 \pm 0.003$ \\
& Cooling & $28.9 \pm 0.1$ & $1.2 \pm 0.8$ & $0.004 \pm 0.002$ & $41.2 \pm 0.1$ & $35.5 \pm 0.8$ & $0.113 \pm 0.003$ \\
DPPC & Heating & $34.2 \pm 0.1$ & $2.7 \pm 0.8$ & $0.009 \pm 0.002$ & $41.4 \pm 0.1$ & $28.1 \pm 0.8$ & $0.089 \pm 0.003$ \\
$\begin{array}{l}+\beta \text {-carotene } \\
(1 \mathrm{~mol} \%)\end{array}$ & Cooling & $28.3 \pm 0.1$ & $0.8 \pm 0.8$ & $0.003 \pm 0.002$ & $40.6 \pm 0.1$ & $27.2 \pm 0.8$ & $0.087 \pm 0.003$ \\
\hline
\end{tabular}



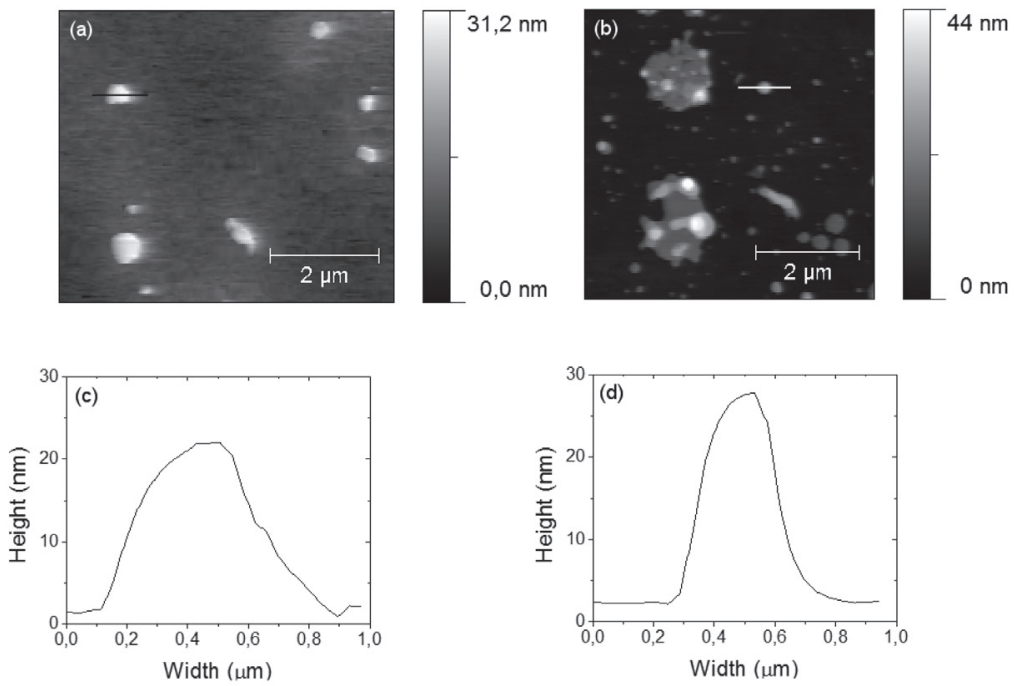

Figure 2. AFM topography of DPPC liposomes containing $1 \mathrm{~mol} \% \beta$-carotene measured using (a) a non-contact mode and (b) a contact mode.

Both experiments were performed in air. The sample was deposited on a glass substrate. Scan size was $5 \mu \mathrm{m} \times 5 \mu \mathrm{m}$. Exemplary profiles of liposomes are shown in (c) and (d) for the vesicle marked on picture (a) and (b), respectively. The measurements were carried out at $25^{\circ} \mathrm{C}$.

\section{AFM measurements}

\section{Topography of liposomes}

The topography of DPPC multilamellar vesicles containing $\beta$-carotene and examined both in contact and non-contact mode in air, are presented in Fig. 2. In both modes we observed spherically-shaped vesicles which were flattened as a result of their adsorption on the glass surface. They show a size distribution from about 100 $\mathrm{nm}$ to about $400 \mathrm{~nm}$. Sometimes they form aggregates with a diameter of about $2 \mu \mathrm{m}$. The structures and sizes of vesicles detected using contact and non-contact mode are similar. Therefore, we may conclude that adhesion between liposomes and the substrate is sufficiently dominant and that possible destructive effects of frictional lateral forces on the structure and size of liposomes can be neglected in the case of the measurements carried on in contact mode.

\section{Temperature dependence of adhesive forces}

We studied the temperature dependence of adhesive forces $\left(F_{A}\right)$ between the $\mathrm{Si}_{3} \mathrm{~N}_{4}$ tip and DPPC in lipo-

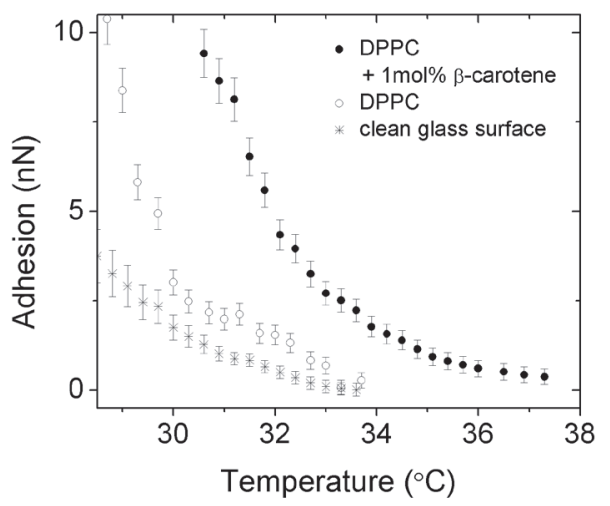

Figure 3. The temperature dependence of the adhesive forces obtained for multilamellar DPPC liposomes, DPPC liposomes containing $1 \mathrm{~mol} \%$ of $\beta$-carotene and clean glass surface.

The applied loading rate was $200 \mathrm{nN} / \mathrm{s}$. somes with and without $\beta$-carotene using AFM. The experiments were performed in air and therefore hydrophobic, viscoelastic, capillary (from liquid contaminants) and specific nonconservative forces may contribute to any detected adhesive forces (for a review see Cappella \& Dietler, 1999). Because liposomes are soft biological materials the tip indents the sample, and therefore the viscoelastic forces can be comparable to the capillary forces. Additionally, if one takes into account that the height of the water layer is limited and lower than in the case of more hydrophilic surfaces, forces characteristic of interactions between liposomes and the silicon nitride tip should make significant contributions to the adhesive forces (Eastman \& Zhu, 1996).

The experimental data presented in Fig. 3 were collected during the heating of the samples. Adhesion was detected during an AFM tip retracting from the sample surface.

For DPPC liposomes containing $\beta$-carotene the adhesive forces show an almost monoexponential decay. They changed from about $10 \mathrm{nN}$ at $31^{\circ} \mathrm{C}$ to $0 \mathrm{nN}$ at $\mathrm{T} \leq 37^{\circ} \mathrm{C}$. However, for pure $\mathrm{DPPC}$ multilamellar vesicles adhesion deviates from this monoexponential behaviour. Moreover, we observed that it is much smaller, by a factor of five at $31^{\circ} \mathrm{C}$, in comparison to a system enriched in $\beta$-carotene, and that is why these forces vanish as early as $\mathrm{T}>34^{\circ} \mathrm{C}$.

In order to estimate what values of capillary forces may contribute to the adhesive forces detected for liposomal systems we performed additional measurements of the adhesive forces for the cleaned glass surface under the same experimental conditions (humidity and loading rate using a cantilever with the same force constant). The data are shown in Fig. 3. We checked that the values of the adhesive forces, mainly capillary in the nature here (Cappella \& Dietler, 1999) have values not larger than about $4 \mathrm{nN}$ at $29^{\circ} \mathrm{C}$ and they decrease with increasing temperature (at $34^{\circ} \mathrm{C}$ they do not exceed $6 \mathrm{pN}$ ) disappearing finally at $\mathrm{T}>34^{\circ} \mathrm{C}$. Moreover, we found that these forces are independent of the loading rate changing from $200 \mathrm{nN} / \mathrm{s}$ to $2000 \mathrm{nN} / \mathrm{s}$ at the established temperature (data not shown). This means that the capillary forces do not depend on the contact time at a given temperature. For example, they are the same for the contact time from about $30 \mathrm{~ms}$ to $30 \mu \mathrm{s}$ at $29^{\circ} \mathrm{C}$, which suggests a constant height of the water layer (Eastman \& Zhu, 1996). Taking into account the results described above and the observation of Fujihira $e t$ al. (1996) that the humidity does not change the capillary forces detected for hydrophobic surfaces and that these forces are smaller in the case of less hydrophilic surfaces, one can deduce that the height of the water layer has to be reduced in the case of liposomes in comparison to the plain glass surface.

Therefore we may conclude that the adhesive forces we detected are mainly related to highly specific interactions between the silicon nitride tip and DPPC liposomes with and without $\beta$-carotene. This conclusion is independently supported by the observation that the value of the jump-off-contact is at least 2-3 times larger for these forces that observed for the capillary forces, when 
the detachment of the tip occurs for its displacement by about $200-500 \mathrm{~nm}$ from the contact position depending on the loading rate. Moreover, we observed the occurrence of attractive forces in the approaching force curves obtained for our liposomes, but only at $\mathrm{T}<31.5^{\circ} \mathrm{C}$ and the mean value of these forces is about $0.11 \pm 0.03$ $\mathrm{nN}$, i.e. one or two orders of magnitude lower than the values of adhesion observed during retraction within the same temperature range. By contrast, the attractive forces detected while the tip approached the glass surface were comparable to the values of the capillary forces obtained from the withdrawal part of the force curves.

To summarize, the adhesive forces, which had increased with the introduction of $\beta$-carotene to DPPC multilamellar liposomes, disappeared when the temperature was raised to about $3^{\circ} \mathrm{C}$.

\section{CONCLUSIONS}

The results of DSC experiments confirmed the presence of two transition states from lamellar to undulledlamellar phase at $35.2^{\circ} \mathrm{C}$ and $34.2^{\circ} \mathrm{C}$, and from gel to liquid crystalline at $41.8^{\circ} \mathrm{C}$ and $41.4^{\circ} \mathrm{C}$ in the heating thermograms obtained for DPPC liposomes with and without $1 \mathrm{~mol} \% \quad \beta$-carotene, respectively. However, in the latter case the transition temperatures were shifted toward lower temperatures, which suggests that the structural reorganization of DPPC multilamellar vesicles is stimulated by this carotenoid. Our AFM results show that $\beta$-carotene, which facilitates pretransition, causes a significant increase in viscoelastic interactions in the liposomes. The adhesive forces, which are dominated by highly specific interactions between the silicon nitride tip and the liposomes as well as by the inner interaction between the lipids which form the structures are not measurable at $34-35^{\circ} \mathrm{C}$ for pure DPPC liposomes, but they are still in the order of $1-2 \mathrm{nN}$ in the presence of $\beta$-carotene under our experimental conditions. At lower temperatures $\left(<33^{\circ} \mathrm{C}\right)$ they are about $2.5-5.0$ times higher in liposomes enriched in $\beta$-carotene. Any significant contribution of capillary forces in these processes can be excluded.

These results demonstrate that AFM is a very sensitive tool for monitoring interactions between the components of lipid vesicles and it provides new information on their reorganization induced by various factors. In particular, using this technique it was possible to observe increased cooperation between the components of DPPC liposomes enriched in $\beta$-carotene. Moreover, it can be concluded that the action of carotenoids as modulators of lipid membrane physical properties is very sensitive to temperature, especially in a temperature range which is close to physiological conditions.

\section{Acknowledgement}

This work was partially supported by Polish Ministry of Science and Higher Education grants for Scientific Research (AGH WFiIS). These studies were performed within the BIONAN project. DSC measurements were carried out with equipment purchased thanks to the financial support of the European Regional Development Fund within the framework of the Polish Innovation Economy Operational Program (contract No. POIG.02.01.00-12-167/08, project Malopolska Center of Biotechnology).

\section{REFERENCES}

Andreeva A, Popova A (2010) Integration of $\beta$-carotene molecules in small liposomes. J Phys: Conf Ser 253: 012066.

Bakowsky H, Richter T, Kneuer C, Hoekstra D, Rothe U, Bendas G, Erhardt C, Bakowsky U (2008) Adhesion characteristics and stability assessment of lectin-modified liposomes for site-specific drug delivery. Biochim Biophys Acta 1778: 242-249.

Bendich A (1993) Biological functions of dietary carotenoids. Ann NY Acad Sci USA 691: 61-67.

Biltonen RL and Lichtenberg D (1993) The use of differential scanning calorimetry as a tool to characterize liposome preparations. Chem Phys Lipids 64: 129-142.

Britton G (2008) Functions of intact carotenoids. In Carotenoids. Natural Functions. Britton G, Liaaen-Jensen S, Pfander, eds, vol 4, pp 189211. Birkhauser Verlag.

Burton GW, Ingold KU (1984) Beta-carotene: an unusual type of lipid antioxidant. Science 224: 569-573.

Cappella B, Dietler G (1999) Force-distance curves by atomic force microscopy. Surf Sci Rep 34: 1-104

De Souza EF, Teschke O (2003) Liposome stability verification by atomic force microscopy. Rev Adv Mater Sci 5: 34-40.

Duzgunes N, Nir S (1999) Mechanisms and kinetics of liposome-cell interactions. Adv Drug Deliv Rev 40: 3-18.

Eastman T, Zhu DM (1996) Adhesion forces between surface-modified AFM tips and a mica surface. Langmuir 12: 2859-2862.

Fujihira M, Aoki D, Okabe Y, Takano H, Hokari H, Frommer J, Nagatani Y, Sakai F (1996) Effect of capillary force on friction force microscopy: a scanning hydrophilicity microscope. Chem Lett 7 : 499-500.

Gruszecki WI, Strzałka K (2005) Carotenoids as modulators of lipid membrane physical properties. Biochim Biophys Acta 1740: 108-115.

Iglič A (2011) Advances in planar lipid bilayers and liposomes. Andreeva A, Popova A, eds, vol 14, pp 294-307. Academic Press.

Jemioła-Rzemińska M, Pasenkiewicz-Gierula M, Strzałka K (2005) The behaviour of $\beta$-carotene in the phosphatidylcholine bilayer as revealed by a molecular simulation study. Chem Phys Lipids 135: 27-37.

Kostecka-Gugała A, Latowski D, Strzałka K (2003) Thermotropic phase behaviour of $\alpha$-dipalmitoylphosphatidylcholine multibilayers is influenced to various extents by carotenoids containing different structural features - evidence from differential scanning calorimetry. Biochim Biophys Acta 1609: 193-202.

Roiter Y, Ornatska M, Rammohan AR, Balakrishnan J, Heine DR, Minko S (2009) Interaction of lipid membrane with nanostructured surfaces. Langmuir 25: 6287-6299.

Sanchez J, Badia A (2003) Atomic force microscopy studies of lateral phase separation in mixed monolayers of dipalmitoylphosphatidylcholine and dilauroylphosphatidylcholine. Thin Solid Films 440: 223-239.

Suwalsky M, Hidalgo P, Strzałka K, Kostecka-Gugała A (2002) Comparative $\mathrm{X}$-ray studies on the interaction of carotenoids with a model phosphatidylcholine membrane. Z. Naturforsch 57c: 129-134.

Telfer A, Pascal A, Gall A (2008) Carotenoids in Photosynthesis. In Carotenoids. Natural Functions. Britton G, Liaaen-Jensen S, Pfander H, eds, vol 4, pp 265-305. Birkhauser Verlag.

Yang YP, Tsay RY (2007) Morphology of compressed dipalmitoyl phosphatidylcholine monolayers investigated by atomic force microscopy. J Lumin 127: 186-191. 